\title{
Superior ductility and strength enhancement of ZK60 magnesium sheets processed by a combination of repeated upsetting and forward extrusion
}

\author{
F. Fereshteh-Saniee ${ }^{\mathrm{a}}$, N. Fakhar ${ }^{\mathrm{a}}$, F. Karami ${ }^{\mathrm{a}}$, R. Mahmudi ${ }^{\mathrm{b}}$ \\ ${ }^{a}$ Department of Mechanical Engineering, Faculty of Engineering, Bu-Ali Sina University, \\ Hamedan 65178, Iran \\ ${ }^{\mathrm{b}}$ School of Metallurgical and Materials Engineering, College of Engineering, \\ University of Tehran, Tehran, Iran
}

Faramarz Fereshteh-Saniee (the corresponding author):

Tel.: +98 81 38292630; Fax: +98 8138292631

ffsaniee@basu.ac.ir

ffsaniee@yahoo.com

Naeimeh Fakhar:

Naemeh.fakhar@gmail.com

Fahimeh Karami:

$\underline{\text { Fahime.karami.ks@gmail.com }}$

Reza Mahmudi:

mahmudi@ut.ac.ir 


\title{
Superior ductility and strength enhancement of ZK60 magnesium sheets processed by a combination of repeated upsetting and forward extrusion
}

\begin{abstract}
This research work is concerned with creation of ZK60 Mg sheets by various combinations of the repeated upsetting (RU) and forward extrusion (Ex) operations. The RU process was conducted with different passes and at $250{ }^{\circ} \mathrm{C}$, whereas the subsequent forward extrusion was performed at $220{ }^{\circ} \mathrm{C}$. Complementary tensile tests together with fractography, and microstructural and textural studies were carried out in order to investigate the influence of the process types and conditions on the material properties of the sheet products. It was found that combination of the RU and Ex operations could result in ductile ZK60 sheets with improved strength and strain hardening capacity. The maximum elongation was achieved after 3 passes of RU followed by Ex process. This processing route also resulted in balanced ultimate strengths in both extrusion and transverse directions with almost the highest strain hardening capacity. The effects of RU number of passes and forward extrusion process on the microstructures, textures, mechanical properties and the fracture of the ZK60 sheets were also investigated and, based on the experimental findings obtained; several important conclusions were drawn and explained in this article.
\end{abstract}

Keywords: Repeated Upsetting (RU) process; Forward sheet extrusion; ZK60 Mg alloy; Mechanical properties, superior ductility.

\section{Introduction}

Nowadays, magnesium alloys are extensively used in various applications such as automotive, aerospace, electronics and, recently, medical industries [1,2]. This is mainly due to the low density, high strength/weight ratio, good machinability and life recyclability of these alloys. Nevertheless, because of hexagonal close packed (hcp) crystal structure and 
limited slip systems of the Mg alloys, they represent poor formability at low temperatures. This drawback has limited the use of these alloys in many applications [3]. However, recent investigations have shown that by significant grain refinement and modification of the material behavior, one can effectively overcome this shortcoming [4].

There are many possible means for microstructural modification of materials and reducing their grain size. Nevertheless, during the past couple of decades, many researchers have been interested in employing severe plastic deformation (SPD) techniques for this purpose. Different sorts of SPD methods have been proposed, among which the equalchannel angular pressing (ECAP) operation is the simplest and the most popular one. Ascribed to application of high compressive forces and occurrence of severe shear deformations via this process, a significant change takes place in the microstructure of the material. Even after a few passes of the ECAP operation, the metal attains an ultra-fine grain structure and due to saturation, any further passes of the process would not improve the microstructure and strength of the alloy [1-4]. However, through a secondary forming operation and creation of greater plastic deformations, more strengthening and modification in the structure of the material would be feasible. For instance, combinations of ECAP and rolling for various materials have resulted in enhancements in their grain structures and mechanical properties $[5,6]$. These two-step forming operations could be attractive for producing metal sheets with fine or ultra-fine grains. Keeping in mind that for superplastic behavior of a material it is necessary to reduce its grain size to less than $10 \mu \mathrm{m}$, it is expected that the fine or ultra-fine grained sheets prepared via such combined forming operations would reasonably exhibit a good superplastic behavior, as already reported for aluminum alloys [7]. Therefore, these modified-structure sheets are suitable candidates for superplastic forming operations in many important applications such as automotive and aerospace industries. 
The ECAP samples are generally straight bars with circular or rectangular cross sections. Although these bars can easily be processed to own an ultrafine grained microstructure, they are not suitable for manufacturing fine grained sheets with appropriate widths. Repeated upsetting (RU) process is a much more convenient SPD operation for this purpose. This technique can be imagined as a couple of back to back 90 degree ECAP in which a rectangular cube is severely deformed into another one with almost the same sizes. This SPD method was first introduced by Talebanpour et al. [8] as dual equal channel lateral extrusion (DECLE). Afterwards, Guo et al. [9] employed this operation for disc samples with a large scale and named it repeated upsetting (RU) process. The main advantage of the RU method, compared with the ECAP technique, is inducing a greater effective strain (1.5) during each pass of the operation [10]. Moreover, this SPD process can be utilized for production of thick metallic plates with an improved microstructure. Based on the above mentioned benefits, RU method was used in this research work to prepare ZK60 thick plates with fine-grained microstructures. These plates were then forwardly extruded into sheets with $1.3 \mathrm{~mm}$ thickness. With this regard, a comprehensive study was carried out to examine the effects of the RU pass number on the mechanical properties of both the RUed and extruded samples.

\section{Experimental methods}

The ZK60 Mg alloy was first cast with $6 \mathrm{wt} \% \mathrm{Zn}, 0.6 \mathrm{wt} \% \mathrm{Zr}$ and the remaining magnesium into blocks with $120 \times 120 \times 20 \mathrm{~mm}$ dimensions. Then these billets were annealed at $400^{\circ} \mathrm{C}$ for $12 \mathrm{hr}$ in order to gain a relatively homogenous microstructure. Afterwards, the thickness of each cast block was reduced by $45 \%$ via a multi-pass rolling process. Between each couple of succeeding passes of the rolling operation, the billet was heated at $400^{\circ} \mathrm{C}$ for 
15 minutes. RU samples were then machined with $50 \mathrm{~mm} \times 50 \mathrm{~mm} \times 10 \mathrm{~mm}$ dimensions from the rolled ZK60 specimens and subsequently annealed at $400^{\circ} \mathrm{C}$ for an hour.

The RU experiments were conducted by means of a 400-KN servo-electrical testing machine with a constant ram velocity of $1 \mathrm{~mm} / \mathrm{min}$. To decrease the friction at elevated temperatures, $\mathrm{MoS}_{2}$ was employed. The heating process was performed by using electrical elements installed in the die set. The billet temperature was also controlled by means of a thermocouple, positioned next to the junction of the die channels. The RU tests were carried out at $250^{\circ} \mathrm{C}$ and up to 5 passes through route B [9]. Fig. 1 illustrates a partially deformed plate via the RU process. Since the RU operation is actually a type of lateral extrusion, the three main directions, namely extrusion direction (ED), transverse direction (TD) and normal direction (ND), are shown in the figure. For using route $\mathrm{B}$, the product of the previous pass should first be rotated $90^{\circ}$ about the ND axis and then located in the vertical channel of the die for doing the subsequent pass [8].

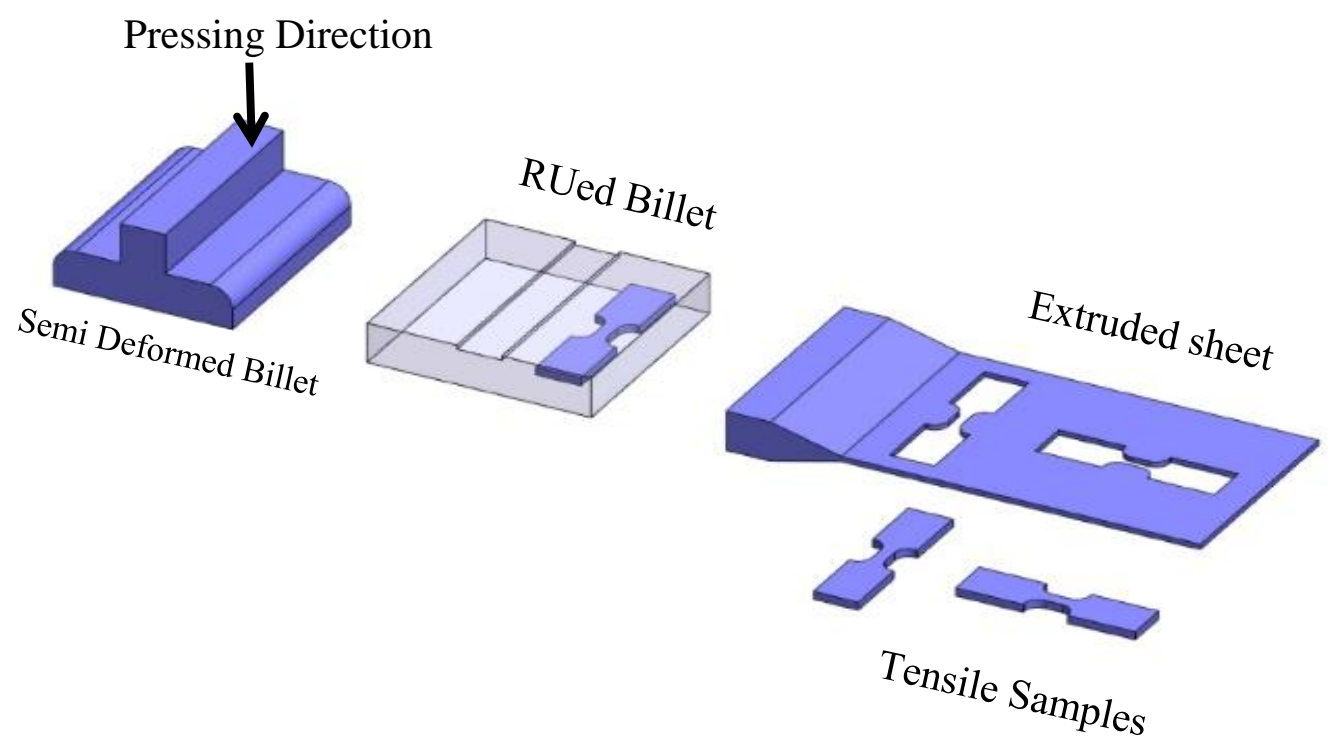

Fig. 1: Schematic illustration of the ZK60 parts formed during and after RU and forward extrusion operations. 
As shown in Fig. 1, the RUed samples were directly (without any change in position) put into another die set for conducting the forward extrusion (Ex) operation and producing the desired ZK60 sheets. By this technique, the extrusion directions of both processes were coinciding. The forward-extrusion die was designed with an extrusion ratio of 7.7 such that it was capable of producing sheets with a thickness of $1.3 \mathrm{~mm}$. Different types of electrical elements were used in the construction of the extrusion die to provide a uniform temperature of $220^{\circ} \mathrm{C}$. The extrusion speed was $0.3 \mathrm{~mm} / \mathrm{min}$. Various RU products, namely 1-passed, 3passed and 5-passed, together with the initially annealed (unRUed) sample were forwardly extruded under the above mentioned conditions. By conducting supplementary experiments, the influences of the RU pass number on the quality and mechanical properties of the finegrained ZK60 sheets were investigated.

To study the effects of RU and Ex processes on the strength and ductility of the ZK60 Mg sheet, various samples were wire cut based on the procedure shown in Fig. 1, for performing tensile tests. Before wire cutting, two 1-mm thick layers at the upper and lower surfaces of the RUed sample were removed in order to eliminate the influence of the interfacial friction on the properties of the RU product. To investigate the anisotropy of the finally extruded ZK60 sheets, tensile specimens were cut in both extrusion and transverse directions (Fig. 1). The gauge length, width and thickness of these samples were $4 \mathrm{~mm}, 3 \mathrm{~mm}$ and $1.3 \mathrm{~mm}$, respectively. Tensile specimens prepared from the purely RUed samples had the same gauge dimensions except that their thickness was $2 \mathrm{~mm}$. Tensile tests were conducted using a 50 KN servo-electrical testing machine at a constant rate and with an initial strain rate of $1 \times 10^{-3} s^{-1}$. To monitor the microstructural evolution of the samples RUed with various pass numbers and extruded at an elevated temperature, a Union Versamet optical microscope was employed. Before observing the microstructures of the samples, they were polished and then etched by a picric acid and ethanol solution. A scanning electron microscope (SEM) was 
also used to perform the fractography of the specimens. Finally, the evolution of the texture after the sheet extrusion process was studied using $\{0002\}$ pole figures.

\section{Results and discussions}

\subsection{Microstructural studies}

Micrographs of the annealed ZK60 alloy together with those of the extruded and/or RUed through different passes are shown in Fig. 2. As Fig. 2a illustrates, after an hour annealing at $400{ }^{\circ} \mathrm{C}$, the average grain size (AGS) of the material was measured to be $40 \mu \mathrm{m}$. For a more convenient comparison, the micrographs of the 1,3 and 5-passed samples of RU operation are arranged in the left column of Fig. 2 and those of the RUed and, then, extruded samples are illustrated in the right column of the figure. Parts $b$ and $c$ of Fig. 2 show bimodal microstructures, in which very fine grains with a size of 1 to $2 \mu \mathrm{m}$ nucleated around very coarse grains. Since the RU and forward extrusion operations were respectively conducted at $250^{\circ} \mathrm{C}$ and $220^{\circ} \mathrm{C}$ temperatures, the recrystallization phenomenon played an important role in microstructural evolution of the alloy. In fact, the bimodal and inhomogeneous microstructure of the ZK60 Mg alloy could be caused by an incomplete recrystallization.

The sheet extrusion was carried out with an extrusion ratio of 7.7 , inducing an average strain of about 2 into the Mg alloy. On the other hand, each pass of the RU process created an average effective strain of 1.5 in the material. Hence, one can conclude that, since the above mentioned process temperatures and the induced strains are quite comparable, both forward extrusion and 1-pass RU operations resulted in bimodal microstructures for the processed ZK60 alloy. Nevertheless, based on Fig. 3, it can be observed that the forward extrusion resulted in relatively finer grains which could mainly be due to the lower process temperature and greater plastic deformation caused by the forward extrusion. 

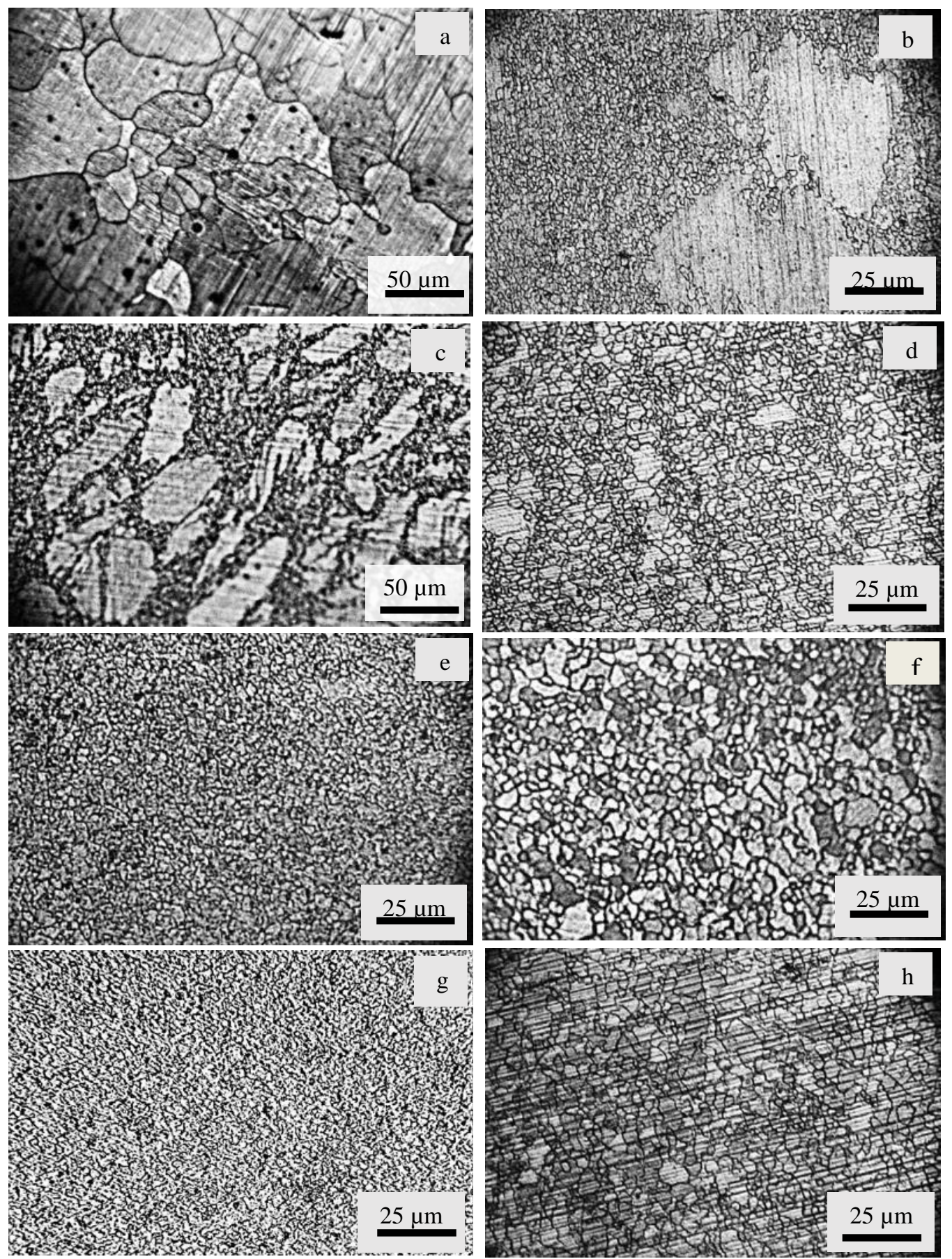

Fig. 2: Micrographs of ZK60 magnesium alloy. (a) annealed as -rolled (b) merely extruded (c, e and g) merely RUed with 1, 3 and 5 passes, respectively. (d,f and h) RUed with 1, 3 and 5 passes and, then, forwardly extruded. 


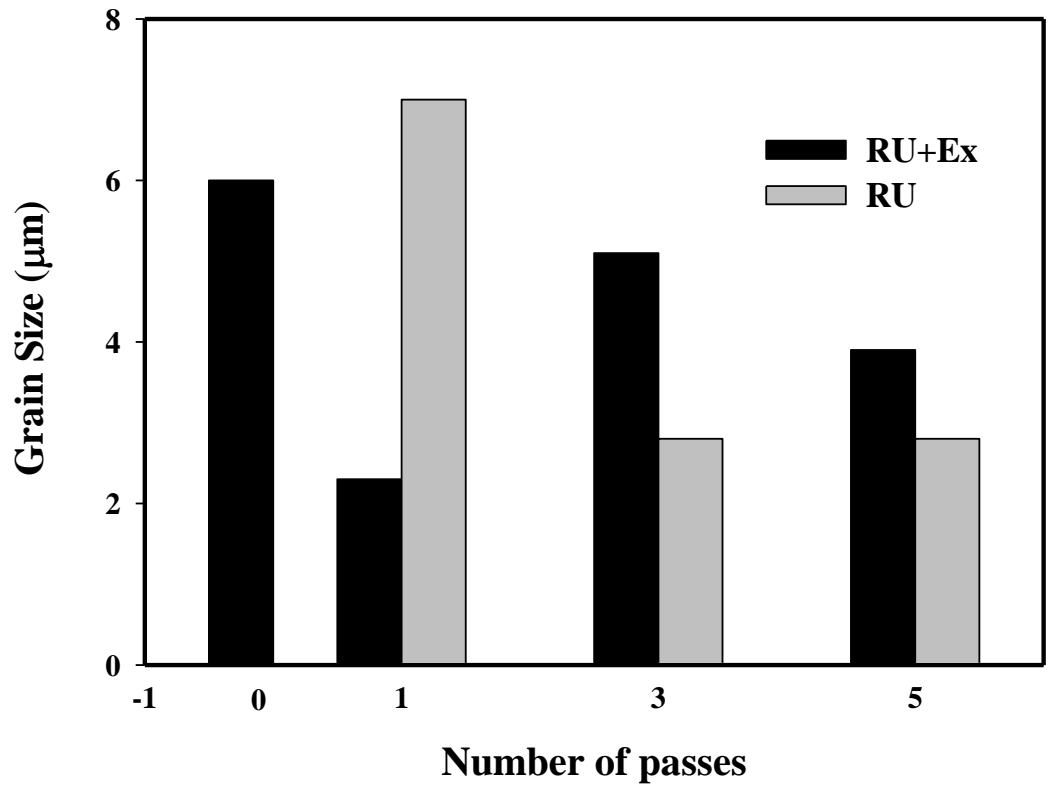

Fig. 3: The average grain size of the ZK60 sample produced by means of RU and RU+Ex operations through various passes.

The presence of a bimodal microstructure during the early stages of the SPD operations was also reported by the previous researchers for ZK60 and other Mg alloys. For instance, Figueiredo and Langdon [11] reported a bimodal microstructure for AZ31 Mg alloy after 1pass of ECAP at $200{ }^{\circ} \mathrm{C}$. They showed that the existence of this type of grain arrangement depended on the initial grain size of the material before performing the ECAP process. A critical grain size was defined which should experimentally be determined [11]. When the extruded AZ31 with an AGS greater than the critical one was ECAPed, a bimodal microstructure was observed after the early passes. However, such a structure was not found after the initial passes of ECAP for the originally extruded ZK60 Mg alloy with an AGS lower than the critical grain size. In other words, the latter case involved a significantly more homogenous microstructure including fine grains [11]. Therefore, regarding the present 
investigation, it was concluded that the initial grain size of the initially rolled ZK60 alloy was greater than the critical one and this fact resulted in bimodal microstructures after the first stage of the RU operation (Fig. 2c) and the forward extrusion process (Fig. 2b). Formation of bimodal microstructures for ZK60 alloy has also been reported for the first and second passes of ECAP at $250{ }^{\circ} \mathrm{C}[12,13]$ as well as after the first pass of the cyclic extrusion-compression (CEC) at $230{ }^{\circ} \mathrm{C}[14]$. The presence of bimodal configuration of grains in Mg alloys was justified by the limited slip systems of these alloys [13]. Performing the RU operation on AZ31 and Mg-Gd alloys resulted in the formation of shear bands during the first and second passes of this process $[9,15]$. These shear bands were oriented along the coarse grains and surrounded by very fine grains. The stress concentration within these shear bands activated more slip systems and this, consequently, intensified dynamic recrystallization. This situation resulted in a more homogenous microstructure after additional passes of the process $[9,15]$.

Fig. 3 illustrates the average grain sizes of various samples processed under different conditions. Except two cases, the greater the number of passes (for both the RU and RU+Ex processes), the smaller is the AGS of the deformed part. The first exception is the relatively close grain sizes of the 3-pass and 5-pass RUed specimens, shown in parts e and g of Fig. 2. This slight grain growth from the 3rd pass to the 5th pass of the RU operation could be due to saturation in the grain refinement after the 3rd pass and heating of the billet for the subsequent passes. Similar fluctuations in the strength of the material after various passes of the SPD operations was also reported for expansion-ECAP of the AZ80 magnesium alloy [16]. The second exceptional case is related to the 3-pass RU+Ex sample, where its AGS is greater than that of the 1-pass RU+Ex specimen, as exhibited in parts $\mathrm{d}$ and $\mathrm{f}$ of Fig. 2. Looking at Fig. 2f, one can find out that the difference between the largest and smallest grains is lower than that of Fig. 2d, implying that the former, which corresponds to the 3-pass RU+Ex, contains a more homogenous microstructure. As explained above, replacement of an 
inhomogeneous and bimodal microstructure with a homogeneous and equi-axed grain structure is a consequence of a more complete recrystallization during the RU and forward extrusion operations and/or static recrystallization during breaks between various stages of the processes. These observations are in agreement with those of the 5-pass RU operation of AZ31 alloy through route B [9]. Creation of ultra-fine and equi-axed grains during the subsequent passes of different SPD operations is also reported for various alloys [13-17].

As a concluding remark, RU significantly reduced the grain size, such that after the first pass it was reduced from $40 \mu \mathrm{m}$ to $7 \mu \mathrm{m}$, and after 3 and 5 passes of the operation it was decreased to about $2.8 \mu \mathrm{m}$. A bimodal microstructure was observed after the 1 st pass, whereas by increasing the pass number, it became more and more homogeneous, such that after the 5th pass of the RU process, a uniform microstructure was obtained. Compared with merely doing forward extrusion, combination of 1-pass RU and forward extrusion provided a sheet with much greater grain refinement. The average grain sizes for these cases were, respectively, about $6 \mu \mathrm{m}$ and $2 \mu \mathrm{m}$. However, conducting forward extrusion after doing RU with greater number of passes (i.e. 3 and 5 passes) resulted in more uniform microstructures but with slightly larger grain sizes, compared with 1-pass RU+Ex operation.

\subsection{Mechanical properties}

Fig. 4 illustrates the yield stresses, ultimate strengths and percentage elongations for different combinations of passes and operations. The values of these parameters together with the relevant strain hardening capacities are summarized in Table 1. As can be seen, for all of the cases the yield and ultimate strengths are improved compared with those of the initial annealed billet. For 1 and 5-pass RUed samples the strength improvements are almost the same and are about $50 \%$ and $36 \%$ for $\sigma_{y}$ (the yield stress) and $\sigma_{u l t}$ (the ultimate tensile strength), respectively. However, the ductility enhancement for the 5-passed specimen is 
quite greater. By conducting the RU operation and increasing the pass number, the percentage elongation gradually increases, in comparison with the undeformed sample. Nevertheless, remarkable declines in $\sigma_{y}, \sigma_{u l t}$ and strain hardening capacity, which is defined as $\sigma_{y} / \sigma_{u l t}$ ratio, of the material can be noticed after the 3rd pass of the RU process. Therefore, one may conclude that to achieve the best improvements in mechanical properties of ZK60 alloy and, at the same time, to have a high strengthening rate; it is preferable to conduct a 1pass RU operation and avoid any further passes of the operation.

Lin et al. [14] reported quite similar observations for CEC processing of ZK60 alloy at $350{ }^{\circ} \mathrm{C}$. They found significant rises in the yield and ultimate strengths of the material after the first pass of the CEC process. Afterwards, by increasing the number of passes the strength decreased gradually up to the 4 th pass. The improvement in the strength after the 1 st pass was attributed to the grain refinement (based on the Hall-Petch relation) because no change was observed in the texture of the material. After the second pass of the CEC operation, due to the texture evolution and reduction in the Schmid factor, the strength of the alloy decreased [14]. Similar situation occurred in the present investigation, except that the bimodal microstructure of the material after the 1st pass of the RU process (Fig. 2c) intensified the strength enhancement of the alloy. Although the average grain size in Fig. $2 \mathrm{~g}$ is equal to that of the 3pass RU product (Fig. 2e), the presence of several larger grains among the fine ones could increase the strength after the 5th pass of the RU process. These larger grains might be created due to the saturation of the grain refinement after the 3rd pass and/or the heating of the billet for the 4th and the 5th passes.

By employing the RU process and increasing the number of passes, based on the elongations reported in Table 1, it is possible to monotonically improve the ductility of the ZK60 alloy under consideration. This was also the situation in the previous investigations $[14,15]$, where various SPD operations were utilized for different Mg alloys. By increasing 
the pass number, the amount of the strain induced into the material is increased, and consequently, the low-angle grain boundaries are gradually converted to high-angle ones. The presence of the high-angle boundaries activates the slip mechanism of the grain boundaries and this, in turn, results in significant ductility enhancement $[13,15]$. It is worthy to mention that the grain boundary slip mechanism can relief the stress concentration caused by the dislocation movement and result in a greater deformation accommodation $[13,15]$.

Fig. $4 c$ also shows the percentage elongation of the sample after different stages of RU and RU+Ex operations. It is obvious from this diagram that after forward extrusion, the elongation in the TD is decreased, whereas in the ED it is considerably increased, compared with the RU process with the same number of passes. Nevertheless, after the 3rd pass, the elongations of the RUed sample and the extruded sheet in the TD are almost the same and, at the same time, it is also significantly improved in the ED. In other words, the best elongation and simultaneously quite high strengths in both extrusion and transverse directions are represented by the 3-pass RU+Ex route.

Fig. 5 illustrates the $\{0002\}$ pole figures of the basal plane for sheets produced with various process conditions. In all figures, most of the basal planes are orientated in the extrusion direction and that is why, in all of the cases, the ED elongation is much greater than the TD one. Even in parts b and d of Fig. 5, this type of texture is intensified, compared with the other two pole figures. For this reason, there are comparatively higher differences in the ED and TD elongations for these processing conditions depicted in Table 1. This sort of basal plane arrangement was also previously reported for rolled [18] and extruded [19] AZ31 Mg alloy. Another point worthy to note is that, based on Fig. 5 the maximum texture intensity belongs to the 3-pass RU+Ex process and that is why the best deformation behavior is represented by the sheet produced by this operation, as shown in the elongation column in Table 1. 
a)

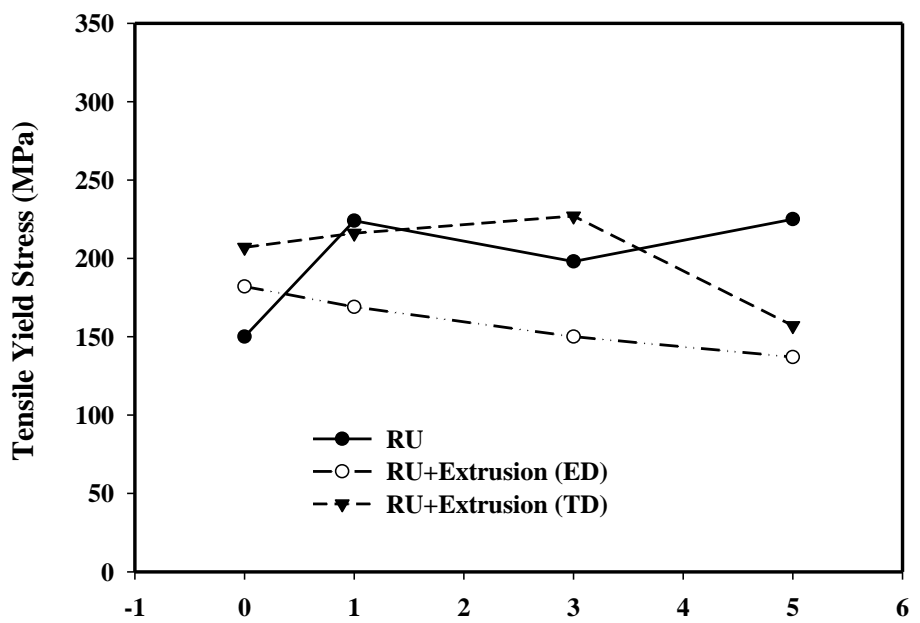

b)

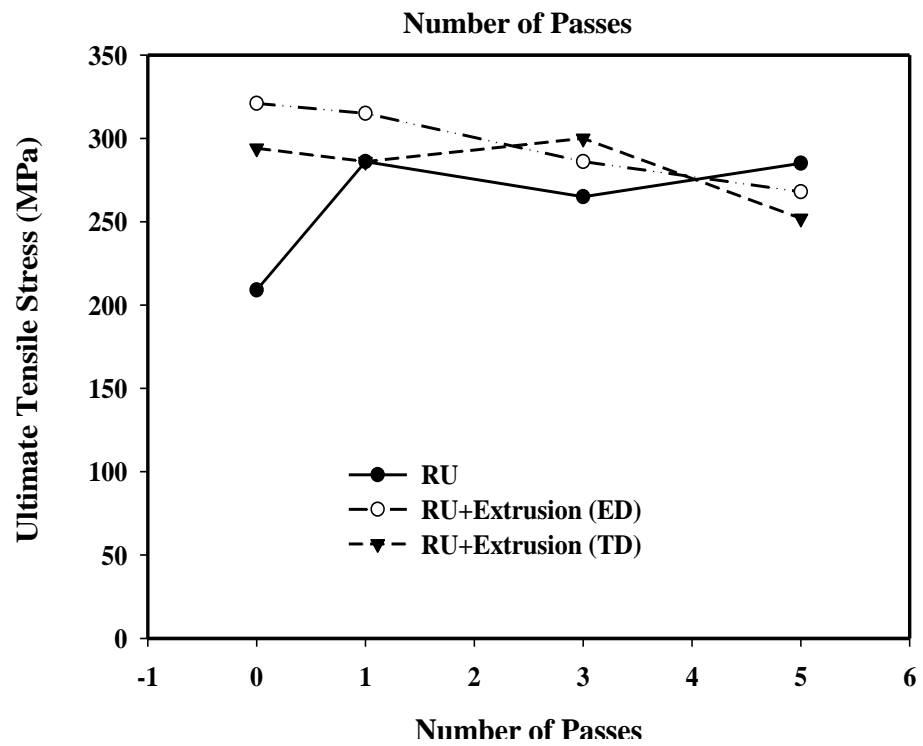

c)

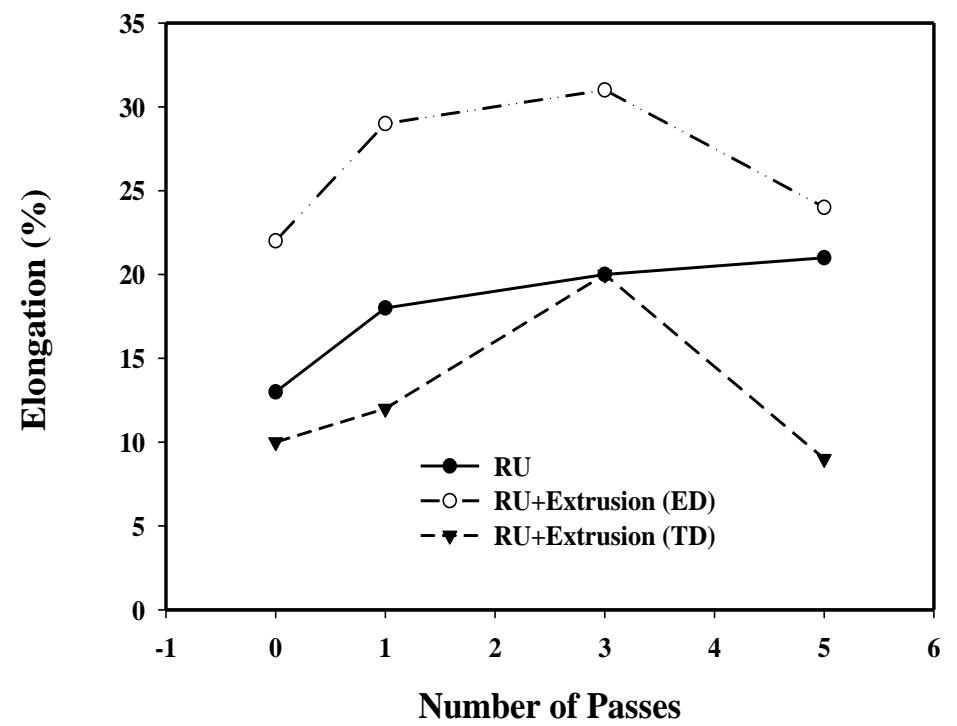

Fig. 4: Variations of the yield stress (a), ultimate stress (b) and percentage elongation (c) with the number of passes performed in RU and RU+Ex processes. 
Table 1: The yield stress, ultimate strength, elongation and strain hardening capacity of ZK60 component produced by RU and RU+Ex operations with various passes.

\begin{tabular}{|c|c|c|c|c|c|c|c|c|c|}
\hline \multirow{2}{*}{\multicolumn{2}{|c|}{ Type of Process }} & \multicolumn{2}{|c|}{$\begin{array}{l}\text { Yield Stress } \\
(\mathrm{MPa})\end{array}$} & \multicolumn{2}{|c|}{$\begin{array}{c}\text { Ultimate } \\
\text { Stress (MPa) }\end{array}$} & \multicolumn{2}{|c|}{$\begin{array}{c}\text { Total } \\
\text { Elongation (\%) }\end{array}$} & \multicolumn{2}{|c|}{$\begin{array}{c}\text { Strain Hardening } \\
\text { Capacity }\end{array}$} \\
\hline & & ED & TD & ED & TD & ED & TD & ED & TD \\
\hline \multicolumn{2}{|c|}{ Annealed } & \multicolumn{2}{|c|}{150} & \multicolumn{2}{|c|}{209} & \multicolumn{2}{|c|}{14} & \multicolumn{2}{|c|}{0.71} \\
\hline \multirow{3}{*}{ RUed } & Pass 1 & \multicolumn{2}{|c|}{224} & \multicolumn{2}{|c|}{286} & \multicolumn{2}{|c|}{21} & \multicolumn{2}{|c|}{0.78} \\
\hline & Pass 3 & \multicolumn{2}{|c|}{198} & \multicolumn{2}{|c|}{265} & \multicolumn{2}{|c|}{24} & \multicolumn{2}{|c|}{0.74} \\
\hline & Pass 5 & \multicolumn{2}{|c|}{225} & \multicolumn{2}{|c|}{285} & \multicolumn{2}{|c|}{25} & \multicolumn{2}{|c|}{0.79} \\
\hline \multicolumn{2}{|c|}{ Extruded } & 174 & 221 & 326 & 316 & 24 & 11 & 0.53 & 0.70 \\
\hline \multirow{3}{*}{$\mathbf{R U}+\mathbf{E x}$} & Pass 1 & 168 & 198 & 319 & 290 & 32 & 13 & 0.52 & 0.68 \\
\hline & Pass 3 & 135 & 190 & 285 & 287 & 34 & 25 & 0.47 & 0.66 \\
\hline & Pass 5 & 116 & 172 & 256 & 264 & 25 & 10 & 0.45 & 0.65 \\
\hline
\end{tabular}

a) Extruded Sheet without RU

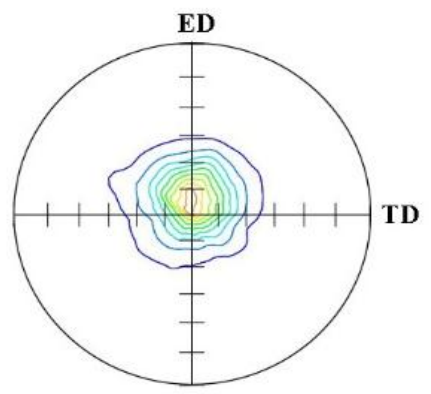

Max intensity: 28.19

c) Extruded Sheet after 3-pass RU

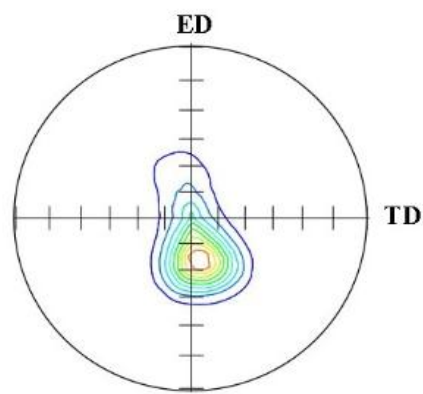

Max intensity: 37.17 b) Extruded Sheet after 1-pass RU

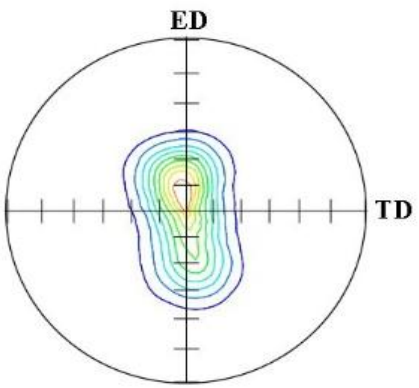

Max intensity: 23.37

d) Extruded Sheet after 5-pass RU

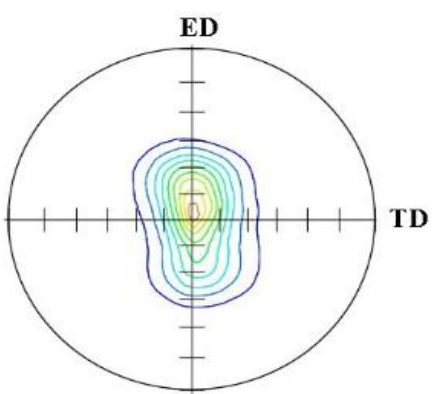

Max intensity: $\mathbf{2 4 . 0 8}$

Fig. 5: $\{0002\}$ pole figures for (a) the merely extruded sheet, (b) 1-pass RU+Ex, (c) 3-pass RU+Ex, and (d) 5-pass RU+Ex ZK60 sheets. 
Based on the results summarized in Table 1, there is a specific trend in the elongation of RUed samples, whereas the strength is decreased from the 1st pass to the 3rd pass, and then, increased from pass 3 to pass 5. By performing forward extrusion after the RU operation, the situation is reversed, i.e. both $\sigma_{y}$ and $\sigma_{u l t}$ of the sheet in both extrusion and transverse directions monotonically decreased, whereas the percentage elongation in the ED and TD increased up to three RU passes and, afterwards, decreased after 5-pass RU+Ex operation. This changing effect of the subsequent forward extrusion is not unusual. For instance, some researchers have claimed that when an ECAP operation was followed by a rolling process, considerable changes in the texture and arrangement of the basal planes were observed which, in turn, affected the material properties of magnesium $[5,6]$ and copper [20]. When a secondary operation after the ECAP process was conducted in the cold condition $[5,6]$, the strength increased and ductility decreased significantly. But when the secondary process was hot, the strength reduced whereas the formability of the sheet improved considerably $[6,7,21]$. In the present investigation, as can be seen in Table 1, by conducting a hot forward extrusion after the RU operation, the elongation was enhanced significantly, the yield strength reduced considerably and slight changes occurred in the ultimate strength of the sheet, in comparison with the purely RUed samples. This situation resulted in a more obvious strain hardening behavior for the RU+Extruded sheet, compared with the relevant purely RUed specimen (Table 1). The last column of Table 1 is assigned to the strain hardening capacity of the deformed samples which is calculated as $\sigma_{y} / \sigma_{u l t}$ ratio for each product. The lower the value of this ratio, more evident and greater is the strain hardening behavior of the deformed alloy. In all the cases, conduction of the forward extrusion decreased the $\sigma_{y} / \sigma_{u l t}$ ratio of the material. Keeping in mind that the extrusion process also increased the ductility of the final sheet, one may conclude that by combination of RU and forward extrusion operations, it is possible to 
provide more ductile ZK60 sheets with an improved strength and good strain hardening capacity for cold forming of the final sheet parts.

Table 2 summarizes the mechanical properties of the ZK60 alloy produced by means of various techniques and operations, including the RU and extrusion processes which are employed in the present research work. It can be seen from this table that the processing techniques utilized in this investigation resulted in ZK60 sheets with a very good ductility and a reasonable strength enhancement.

Table 2: The mechanical properties of the ZK60 alloy conventionally and/or severely deformed by means of various metal forming techniques.

\begin{tabular}{|c|c|c|c|c|c|c|}
\hline No. & $\begin{array}{c}\sigma_{\mathbf{Y}} \\
(\mathbf{M P a})\end{array}$ & $\begin{array}{l}\sigma_{\text {ULT }} \\
(\mathbf{M P a})\end{array}$ & $\begin{array}{c}\text { Total } \\
\text { Elongation } \\
(\%)\end{array}$ & $\begin{array}{c}\text { Strain Rate } \\
\qquad\left(\mathrm{s}^{-1}\right)\end{array}$ & $\begin{array}{l}\text { Processing } \\
\text { Technique }\end{array}$ & Ref. No. \\
\hline 1 & 250 & 350 & 6 & $2 \times 10^{-3}$ & $\begin{array}{c}\text { Twin roll cast+Rolling } \\
\text { at } 350^{\circ} \mathrm{C}\end{array}$ & 22 \\
\hline 2 & 199 & 306 & 24 & $6.7 \times 10^{-4}$ & Hot rolling at $400^{\circ} \mathrm{C}$ & 23 \\
\hline 3 & 278 & 342 & 18 & ----------- & $\begin{array}{l}\text { Twin roll cast }+ \\
\text { Rolling at } 300^{\circ} \mathrm{C}\end{array}$ & 24 \\
\hline 4 & 200 & 360 & 25 & $5 \times 10^{-4}$ & $12 \mathrm{P}$ ECAP at $300^{\circ} \mathrm{C}$ & 5 \\
\hline 5 & 396 & 440 & 9 & $5 \times 10^{-4}$ & $\begin{array}{l}\text { 12P ECAP at } 300{ }^{\circ} \mathrm{C}+ \\
\text { Cold rolling }\end{array}$ & 5 \\
\hline 6 & 150 & 310 & 30 & $3.3 \times 10^{-3}$ & $4 \mathrm{P}$ ECAP at $250{ }^{\circ} \mathrm{C}$ & 13 \\
\hline 7 & 215 & 289 & 37 & $1 \times 10^{-3}$ & $4 \mathrm{P}$ CEC at $230^{\circ} \mathrm{C}$ & 14 \\
\hline 8 & 225 & 285 & 25 & $1 \times 10^{-3}$ & $5 \mathrm{P}$ RU at $250^{\circ} \mathrm{C}$ & $\begin{array}{c}\text { The present } \\
\text { work }\end{array}$ \\
\hline 9 & 135 & 285 & 34 & $1 \times 10^{-3}$ & $\begin{array}{l}3 \mathrm{P} R U \text { at } 250{ }^{\circ} \mathrm{C}+ \\
\text { Sheet Extrusion at } \\
220{ }^{\circ} \mathrm{C}\end{array}$ & $\begin{array}{l}\text { The present } \\
\text { work }\end{array}$ \\
\hline
\end{tabular}

As a summary, considering just RU process (without doing any forward extrusion), it should be claimed that the elongation as well as the yield and ultimate strengths were significantly increased after the 1st pass, compared with those of the as-received ZK60 alloy. The elongation is monotonically increasing with the pass number such that the best 
formability was obtained after the 5th pass of the process. Nevertheless, slight reductions in the yield and ultimate strengths took place after the 3rd pass, whereas after the 5 th pass, they were recovered to those of the 1st pass. Performing RU (with various passes) before forward extrusion resulted in sheets with lower strengths in both the transverse and extrusion directions, whereas the elongation was improved in both the directions. The greatest elongation was obtained via 3-pass RU+Ex process. Such a superior ductility (i.e. 34\% elongation) for ZK60 magnesium sheet at the room temperature has been very encouraging.

\subsection{Fractography}

Fractography of the ZK60 alloy before and after RU operation with different passes were performed and the relevant SEM images were demonstrated in Fig. 6. Fig. 6a shows that before processing by RU, the fractured surface of the specimen contains cleavage facets which are formed as a river pattern in the fracture direction. The presence of cleavage facets is a sign of brittle fracture of the as-rolled ZK60 alloy. This rupture type, which is due to deformations caused by the twinning mechanism, commonly occurs for the magnesium alloys at room temperature [13]. By conducting the RU operation and when the pass number increases, the fracture surfaces indicate much more dimples and cup-shape pits, implying that the material behavior is gradually changed from brittle to ductile. This pattern is more pronounced for samples RUed with 3 or 5 passes (Figs. 6c and 6d). This remark is in agreement with the associated elongations gained from the tensile tests (Table 1), where the maximum values of elongations of RUed specimens are respectively found for the 3-passed and 5-passed products. It has been claimed that different shapes and sizes of the dimples after various passes of ECAP of ZK60 were due to their nucleation, growth and coalescence during the fracture of the sample [13]. More or less, this situation can be observed in parts b to d of Fig 6. 

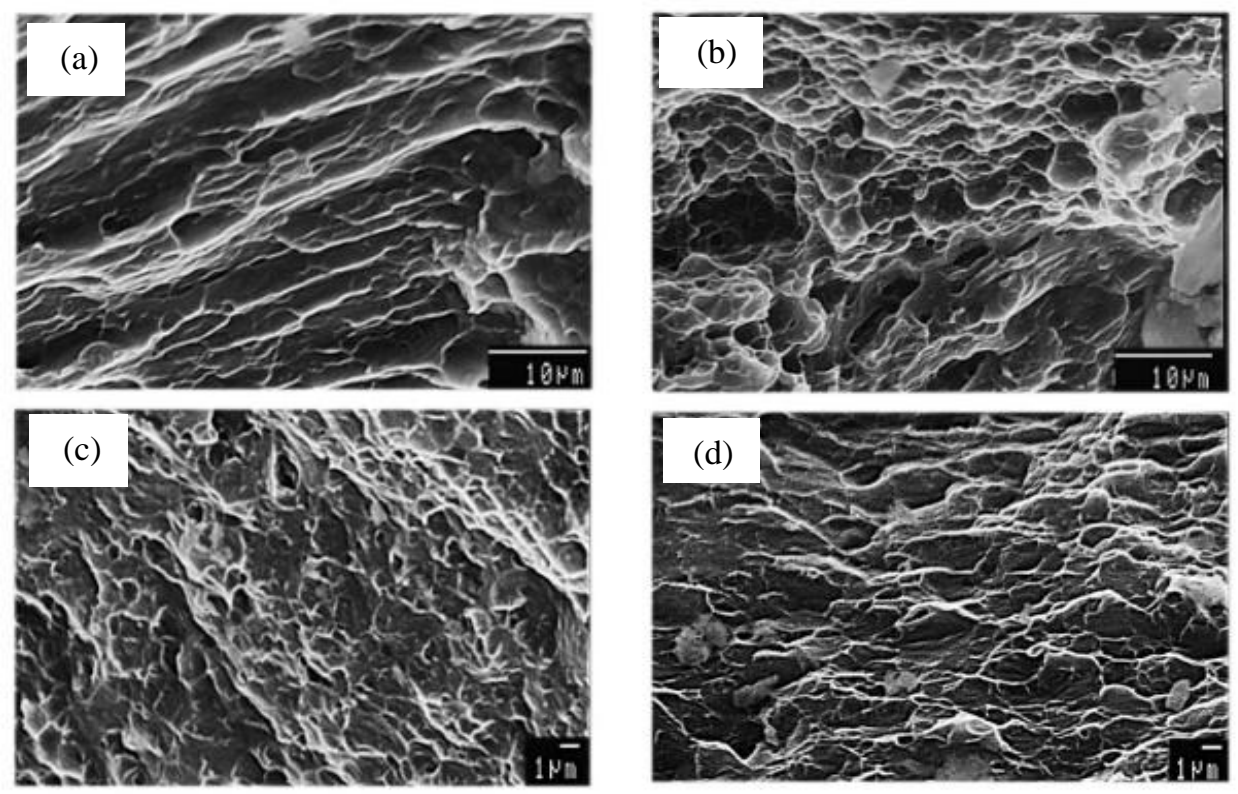

Fig. 6: SEM images of the fractured surfaces of the tensile test specimen for (a) the annealed as-rolled (b) 1-pass RUed, (c) 3-pass RUed and (d) 5-pass RUed ZK60 magnesium alloy.

\section{Conclusions}

Based on the results obtained and observations made in the present investigation, the conclusions can be summarized as below:

- Combining the RU and forward extrusion processes, especially as a 3-pass RU+Ex operation, one can achieve considerably ductile ZK60 sheets with an improved strength as well as good strain hardening capacity, which are all beneficial for subsequent cold plastic deformation to obtain the final sheet part.

- The main advantages of performing a 3-pass RU+Ex process for ZK60 alloy are attaining the maximum elongations in both extrusion and transverse directions, providing high ultimate strength for these directions and offering almost the best strain hardening capacity for the material. 
- For a maximum strengthening rate, one may employ 1-pass RU operation for plastic forming of the bulk ZK60 Mg alloy. By this technique, compared with the as-rolled billet, the yield stress, ultimate strength and the elongation of the material can be improved about 50\%, 37\% and 38\%, respectively.

- In comparison with the purely extruded products, the 3-pass RU+Ex operation provided ZK60 sheets with 50\% improvement in the percentage elongation but lower $\sigma_{y}$ and $\sigma_{u l t}$

- The pole figures showed that most of the basal planes were oriented in the extrusion direction and, for this reason, in all the RU+Extruded sheets the percentage elongation in ED was much greater than that of the transverse direction. Moreover, the maximum texture intensity was obtained for the sheet gained by 3-pass RU+Ex operation which demonstrated the best deformation behavior.

- Before performing the RU process, the SEM image of the fractured surface of the ZK60 alloy illustrated cleavage facets and river patterns in fracture direction, implying a brittle fracture. However by performing the RU operation and increasing the pass number, the fracture surfaces of the sample contained more dimples and cup shape pits, showing a ductile type of rupture. Fractography observations confirmed the experimental findings gained from the tensile tests.

\section{Acknowledgments}

The research work reported here was partially supported by the Iran National Science Foundation (INSF) with grant number 92014140. The authors appreciate the financial support from this organization. 


\section{References}

[1] S. A. Torbati-Sarraf and T. G. Langdon, "Properties of a ZK60 magnesium alloy processed by high-pressure torsion," J. Alloys Compd., 613, 357-363, 2014.

[2] Q. Chen, D. Shu, C. Hu, Z. Zhao and B.Yuan, "Grain refinement in an as-cast AZ61 magnesium alloy processed by multi-axial forging under the multitemperature processing procedure," Mater. Sci. Eng. A, 541, 98-104, 2012.

[3] A. Ma, J. Jiang, N. Saito, I. Shigematsu, Y. Yuan, D. Yang and Y. Nishida, "Improving both strength and ductility of a Mg alloy through a large number of ECAP passes," Mater. Sci. Eng. A, 513-514, 122-127, 2009.

[4] K. Matsubara, Y. Miyahara, Z. Horita and T. G. Langdon, "Developing superplasticity in a magnesium alloy through a combination of extrusion and ECAP," Acta Mater., 51, 3073-3084, 2003.

[5] Y. Yuan, A. Ma, X. Gou, J. Jiang, F. Lu, D. Song and Y. Zhu, "Superior mechanical properties of ZK60 mg alloy processed by equal channel angular pressing and rolling," Mater. Sci. Eng. A, 63, 45-50, 2015.

[6] F. Lu, A. Ma , J. Jiang , J. Chen, D. Song , J. Chen and D. Yang, "Enhanced mechanical properties and rolling formability of fine-grained $\mathrm{Mg}-\mathrm{Gd}-\mathrm{Zn}-\mathrm{Zr}$ alloy produced by equal channel angular pressing," J. Alloys Compd., 643, 28-33, 2015.

[7] H. Akamatsu, T. Fujinami, Z. Horita and T.G. Langdon, "Influence of rolling on the superplastic behavior of an Al-Mg-Sc alloy after ecap," Scripta mater. 44, 759-764, 2001.

[8] B. Talebanpour, R. Ebrahimi and K. Janghorban, "Microstructural and mechanical properties of commercially pure aluminum subjected to Dual Equal Channel Lateral Extrusion," Mater. Sci. Eng. A, 527, 141-145, 2009.

[9] W. Guo, Q.D. Wang, B. Ye, M.P. Liu, T. Peng, X.T. Liu and H. Zhou, "Enhanced microstructure homogeneity and mechanical properties of AZ31magnesium alloy by repetitive upsetting," Mater. Sci. Eng. A, 540, 115-122, 2012.

[10] B. Talebanpour and R. Ebrahimi, "Upper-bound analysis of dual equal channel lateral extrusion," Mater. Des., 30, 1484-1489, 2009.

[11] R. B. Figueiredo and T. G. Langdon, "Principles of grain refinement in magnesium alloys processed by equal-channel angular pressing," J. Mater. Sci., 44, 4758-4762, 2009. 
[12] X. Zhang, L. Hua, and Y. Liu, "FE simulation and experimental investigation of ZK60 magnesium alloy with different radial diameters processed by equal channel angular pressing,” Mater. Sci. Eng. A, 535, 153-163, 2012.

[13] F. D. Dumitru, O. F. Higuera-Cobos, and J. M. Cabrera, "ZK60 alloy processed by ECAP: Microstructural, physical and mechanical characterization," Mater. Sci. Eng. A, 594, 32-39, 2014.

[14] J. Lin, Q. Wang, L. Peng, and H. J. Roven, "Microstructure and high tensile ductility of ZK60 magnesium alloy processed by cyclic extrusion and compression," J. Alloys Compd., 476, 441-445, 2009.

[15] Y. He, Q. Pan, Y. Qin, X. Liu, W. Li, Y. Chiu, and J. J. J. Chen, "Microstructure and mechanical properties of ZK60 alloy processed by two-step equal channel angular pressing,” J. Alloys Compd., 492, 605-610, 2010.

[16] S. Sepahi-Boroujeni, F. Fereshteh-Saniee, "The influences of the expansion equal channel angular extrusion operation on the strength and ductility of AZ80 magnesium alloy", Mater. Sci. Eng. A, 636, 249-253, 2015.

[17] H. Zhou, B.Ye, Q.D. Wang and W. Guo, "Uniform fine microstructure and random texture of Mg-9.8Gd-2.7Y-0.4Zr magnesium alloy processed by repeated upsetting deformation," Mater. Lett. 83, 175-178, 2012.

[18] L. Jin-Ru, C. Xing-Pin, X. Ren-Long, H. Guang-Jie and L. Qing, "Comparison of microstructure and properties of AZ31 mg alloy sheet produced through different routes", Trans. Nonferrous. Met. Soc. China, 18, 194-199, 2008.

[19] H.K. Lin, J.C. Huang, T.G. Langdon, "Relationship between texture and low temperature superplasticity in an extruded AZ31 mg alloy processed by ecap." Mater. Sci. Eng. A, 402, 250-257, 2005.

[20] N.D. Stepanov, A.V. Kuznetsov, G.A. Salishchev, G.I. Raab and R.Z. Valiev, "Effect of cold rolling on microstructure and mechanical properties of copper subjected to ECAP with various number of passes," Mater. Sci. Eng. A, 54, 105-115, 2012.

[21] M. Cabibbo, M. El Mehtedi, L. Barone, E.F. Prados and M. Ferrante, "Mechanical properties at high temperature of an AA3004 after ECAP and cold/hot rolling," Rev. Adv. Mater. Sci. 25, 183-188, 2010.

[22] X. Gong, W. Gong, S.B. Kang and J.H. Cho, " Effect of warm rolling on microstructure and mechanical properties of twin roll casted ZK60 alloy sheets," Mater. Res., 18(2), 360-364, 2015. 
[23] W. Xin, C.W. Zhen, H.L. Xi, W.G. Jun and W. Er-De, "Microstructure refining and property improvementof ZK60 magnesium alloy by hot rolling," Trans. Nonferrous. Met. Soc. China, 21, 226-242, 2011.

[24] H. Chen, SB. Kang, H. Yu, J. Cho, H.W. Kim and G. Min, "Effect of heat treatment on microstructure and mechanical properties of twin roll cast and sequential warm rolled ZK60 alloy sheets," J. Alloys Compd, 476, 324-328, 2009.

\section{Figure Captions:}

Fig. 1: Schematic illustration of the ZK60 parts formed during and after RU and forward extrusion operations.

Fig. 2: Micrographs of ZK60 magnesium alloy. (a) annealed as -rolled (b) merely extruded (c, e and g) merely RUed with 1, 3 and 5 passes, respectively. (d,f and h) RUed with 1, 3 and 5 passes and, then, forwardly extruded.

Fig. 3: The average grain size of the ZK60 sample produced by means of RU and RU+Ex operations through various passes.

Fig. 4: Variations of the yield stress (a), ultimate stress (b) and percentage elongation (c) with the number of passes performed in RU and RU+Ex processes.

Fig. 5: $\{0002\}$ pole figures for (a) the merely extruded sheet, (b) 1 pass RU+Ex, (c) 3-pass RU+Ex, and (d) 5-pass RU+Ex ZK60 sheets.

Fig. 6: SEM images of the fractured surfaces of the tensile test specimen for (a) the annealed as-rolled (b) 1-pass RUed, (c) 3-pass RUed and (d) 5-pass RUed ZK60 magnesium alloy.

\section{Table Captions:}

Table 1: The yield stress, ultimate strength, elongation and strain hardening capacity of ZK60 component produced by RU and RU+Ex operations with various passes.

Table 2: The mechanical properties of the ZK60 alloy conventionally and/or severely deformed by means of various metal forming techniques. 